\title{
Alternative Use of Light Emitting Diodes in an Activated Charcoal-Supported Photocatalyst Reactor for the Control of Volatile Organic Compounds
}

\author{
Sung-Bong $\mathrm{YANG}^{1}$, Mee-Seon $\mathrm{YU}^{1}$, Jong-Soon $\mathrm{KIM}^{2}$, Wan-Kuen $\mathrm{JO}^{3, *}$ \\ ${ }^{1}$ Department of Chemistry, College of Natural Science, University of Ulsan, Ulsan, 680-749, Korea \\ ${ }^{2}$ NGETech Inc, Busan, Korea \\ ${ }^{3}$ Department of Environmental Engineering, Kyungpook National University, Daegu, 702-701, Korea
}

\begin{abstract}
The applicability of ultraviolet-light emitting diodes (LEDs) as a light source for photocatalysis using granular activated charcoal (GAC) impregnated with transition metal-enhanced photocatalysts for the control of volatile organic compounds (VOCs) was investigated. Two target compounds (toluene and methyl mercaptan) were selected to evaluate the removal activities of the $\mathrm{TiO}_{2} / \mathrm{GAC}$ composites. The photocatalysts were prepared by a sol-gel method. Methyl trimethoxy silane was added as a precursor sol solution to bind the photocatalyst with the GAC. Metal $\left(\mathrm{Zn}^{2+}, \mathrm{Fe}^{3+}, \mathrm{Ag}^{+}\right.$, and $\left.\mathrm{Cu}^{2+}\right)$ enhanced $\mathrm{TiO}_{2} / \mathrm{GAC}$ composites were prepared and tested for their photocatalytic activities under $400 \mathrm{~nm}$ LED irradiation. The specific surface area (SSA) and the surface chemical composition of the prepared composites were investigated. The SSAs of all the impregnated composites were similar to those of pure GAC. Both field emission-scanning electron microscopy and energy dispersive spectroscopic analysis confirmed that titanium and the impregnated metals were deposited on the surface of the adsorbent. The breakthrough time for GAC toward toluene or methyl mercaptan gas increased upon photocatalytic impregnation and LED illumination. Using different binders affected the breakthrough time of the $\mathrm{TiO}_{2} / \mathrm{GAC}$ composite and the addition of zinc oxide to TiO $\mathrm{in}$ creased the VOC removal capacity of the GAC composite.
\end{abstract}

Key words: granular activated charcoal; titania; sol-gel method; light emitting diode; surface chemical composition; zinc oxide CLC number: O643 Document code: A

Received 22 November 2010. Accepted 24 January 2011.

*Corresponding author. Tel: +82-53-950-6584; Fax: +82-53-950-6579; E-mail: wkjo@knu.ac.kr

This work was supported by the Korea Institute of Environmental Science and Technology.

English edition available online at Elsevier ScienceDirect (http://www.sciencedirect.com/science/journal/18722067).

Volatile organic compounds (VOCs) in industrialized urban areas originate primarily from industrial processes such as petrochemical production, storage and distribution, solvent usage, and motor vehicle emissions [1,2]. These compounds are generally detected at high concentration levels in an industrialized urban atmosphere [1,3]. Many VOCs are toxic or potentially toxic to humans [4]. In addition, atmospheric VOCs act as precursors for the formation of secondary air pollutants such as ozone, aldehydes, and organic aerosols [5], and certain VOCs react with ozone to form secondary pollutants such as formaldehyde and organic aerosols [6]. These VOC characteristics require the control of emission sources to minimize health risks from environmental exposure.

Adsorption by activated charcoal (AC) has been widely used for the purification of industrial or non-industrial air streams containing VOCs because of its high pore volume and its large exposed surface area to volume ratios [7-9]. However, a limitation of the $\mathrm{AC}$ application to industrial
VOC controls is that upon saturation it needs to be exchanged for a new one or regenerated [10]. Recently, a photocatalytic process has been shown to be an alternative technique because it provides for the absolute reduction of environmental pollutants rather than transferring pollutants from the gas or water phase to the solid phase [11-13]. Moreover, photocatalytic decomposition is considered to be an attractive $\mathrm{AC}$ regeneration technique $[14,15]$. Because of their modular characteristics and the reactor's low pressure drop, photocatalytic reactors can easily be incorporated into existing AC systems. For example, Tao et al. [15] reported that $\mathrm{TiO}_{2}$ loaded onto AC could be effectively applied to the regeneration of $\mathrm{AC}$ by methanol decomposition in pulp and paper mills as methanol is adsorbed on the surface of the adsorbent and the photocatalyst. This occurs without having a significant impact on the adsorption capacity of the AC.

Photocatalytic processes require light illumination for the activation of photocatalysts. Recently, light-emitting diodes (LEDs) have received an increasing amount of interest be- 
cause they have several advantages over conventional light sources [16]. LEDs are more efficient in converting electricity into light because of their high quantum yields, which are close to unity resulting in low electricity consumption. Unlike other water pollution applications, LEDs have rarely been used for the photocatalysis of air pollutants $[17,18]$. Ghosh et al. [17] reported that LED performance was superior to sunlight and was similar to a conventional lamp for the photocatalytic oxidation of liquid-phase 4-chlorophenol. To the best of our knowledge, LEDs have not been used for the combined adsorption and heterogeneous photocatalysis of air pollutants. Accordingly, in this study we evaluated the application of UV-LEDs to various AC-supported photocatalysts for the removal of two VOCs (toluene and methyl mercaptan). Toluene was chosen as a model VOC because it belongs to a major VOC group that is frequently encountered in industrialized urban atmospheres [1,3]. Methyl mercaptan was investigated because it is a major odorous sulfur-containing compound with a low odor threshold value $(5 \mathrm{ppm})$ and it has various adverse health effects $[19,20]$. We also examined the characteristics of the prepared $\mathrm{TiO}_{2} / \mathrm{GAC}(\mathrm{GAC}=$ granular activated charcoal $)$ and metal-enhanced $\mathrm{TiO}_{2} / \mathrm{GAC}$ composites using the BrunauerEmmett-Teller (BET) method, field emission-scanning electron microscopy (FE-SEM), and energy dispersive spectroscopy (EDS).

\section{Experimental}

\subsection{Preparation of catalyst samples}

Two types of $\mathrm{TiO}_{2}\left(\mathrm{TiO}_{2}(\mathrm{I})\right.$ and $\left.\mathrm{TiO}_{2}(\mathrm{II})\right)$ and four types of metal-enhanced $\mathrm{TiO}_{2}$ (Ag-enhanced $\mathrm{TiO}_{2}, \mathrm{Cu}$-enhanced $\mathrm{TiO}_{2}$, Fe-enhanced $\mathrm{TiO}_{2}$, and $\mathrm{Zn}$-enhanced $\mathrm{TiO}_{2}$ ) photocatalysts were prepared for this study. For the preparation of $\mathrm{TiO}_{2}(\mathrm{I})$ and $\mathrm{TiO}_{2}(\mathrm{II})$, a $\mathrm{TiO}_{2}$ sol solution was initially prepared by hydrolyzing $\mathrm{Ti}(\mathrm{OPri})_{4}$ (titanium tetraisopropoxide, Junsei, 99\%). A $1.0 \mathrm{~mol} / \mathrm{L}$ solution of $\mathrm{Ti}(\mathrm{OPri})_{4}$ was added slowly to a deionized water/ethanol (Ducksan Pure Chem., 99.9\%) solution containing $2 \mathrm{~mol} / \mathrm{L} \mathrm{HCl}$ (Junsei, 35\%) or $\mathrm{HNO}_{3}$ (Junsei, $60 \%-62 \%$ ) while heating at $70-80{ }^{\circ} \mathrm{C}$ for 2 h. After cooling the sol solution containing the $\mathrm{TiO}_{2}$ or metal $/ \mathrm{TiO}_{2}$ to room temperature, $0.50 \mathrm{~mol} / \mathrm{L}$ methyltrimethoxy silane (MTMS, $\mathrm{CH}_{3} \mathrm{Si}\left(\mathrm{OCH}_{3}\right)_{3}$, Aldrich) was added as a coupling agent. The addition of MTMS to the sol solution turned the transparent solution turbid and this solution is abbreviated as $\mathrm{TiO}_{2}(\mathrm{I})$. In addition, a portion of the MTMS was mixed with distilled water and alcohol and transformed into $\left(\mathrm{CH}_{3} \mathrm{SiO}_{1.5}\right)_{n}$. This $\mathrm{TiO}_{2}$ solution is designated $\mathrm{TiO}_{2}$ (II). The transformed silane acts as a binder for the preparation of the metal-impregnated $\mathrm{TiO}_{2}$ solutions.
The four metal-enhanced $\mathrm{TiO}_{2}$ photocatalysts were prepared following a procedure from previous studies [21-24]. Copper(II) acetylacetonate $\left(\mathrm{C}_{10} \mathrm{H}_{14} \mathrm{CuO}_{4}\right.$, Aldrich, $\left.99 \%\right)$, iron(III) acetylacetonate $\left(\mathrm{Fe}\left(\mathrm{C}_{5} \mathrm{H}_{8} \mathrm{O}_{2}\right)_{3}\right.$, Aldrich, 97\%), zinc(II) acetylacetonate $\left(\mathrm{Zn}\left(\mathrm{C}_{5} \mathrm{H}_{7} \mathrm{O}_{2}\right)_{2}\right.$, TCI $)$, cobalt(III) acetylacetonate $\left(\mathrm{Co}\left(\mathrm{C}_{5} \mathrm{H}_{8} \mathrm{O}_{2}\right)_{3}\right.$, Aldrich), and silver nitrate $\left(\mathrm{AgNO}_{3}\right.$, Junsei) were used for the impregnation of metals into $\mathrm{TiO}_{2}$.

GAC (Hanil Green granular charcoal; 5-mm in length and 2.5-mm in diameter; before use, the GAC was oven-dried at $200{ }^{\circ} \mathrm{C}$ for $1 \mathrm{~h}$ ) was impregnated with the prepared $\mathrm{TiO}_{2}(\mathrm{I})$, $\mathrm{TiO}_{2}$ (II), and metal-enhanced $\mathrm{TiO}_{2}$ photocatalysts using a spray-coating method. A monolayer of the GAC was spread on a wide tray and a coating solution of $\mathrm{TiO}_{2}$ or metal-enhanced $\mathrm{TiO}_{2}$ (solid content $2 \%$ ) was sprayed onto the GAC ( $10 \%$ by weight). The sprayed GAC was air-dried and heated in an oven at $200{ }^{\circ} \mathrm{C}$ for $1 \mathrm{~h}$. Surface area and porosimetry measurements were carried out using a Micrometrics ASAP2010 apparatus. A field emission-scanning electron microscopy (FE-SEM) with energy dispersive spectroscopy (EDS) (FE-SEM, JEOL, JSM-6500F) was used to examine the surfaces of the $\mathrm{TiO}_{2}(\mathrm{I}), \mathrm{TiO}_{2}(\mathrm{II})$, and metal-enhanced $\mathrm{TiO}_{2} / \mathrm{GAC}$ composites.

\subsection{Experimental procedure}

A schematic diagram for the experiments carried out in this study is shown in Fig. 1. A prepared photocatalyst/GAC composite was placed on the porous glass plate inside a glass cylinder $(3.5-\mathrm{cm}$ diameter and $20-\mathrm{cm}$ height). The composite $(0.1 \mathrm{~g})$ was evenly spread onto the glass plate. 400-nm (MS-L510UVHU) and 365-nm (MS-C510UV-36) LEDs were used for the activation of the photocatalytic reaction. Their optical outputs are shown in Fig. 2. The 365 $\mathrm{nm}$ and $400 \mathrm{~nm}$ LEDs are $5 \mathrm{~mm}$ in diameter and had optical power outputs of $21-29 \mathrm{~mW}$ and $4-6 \mathrm{~mW}$, respectively. The

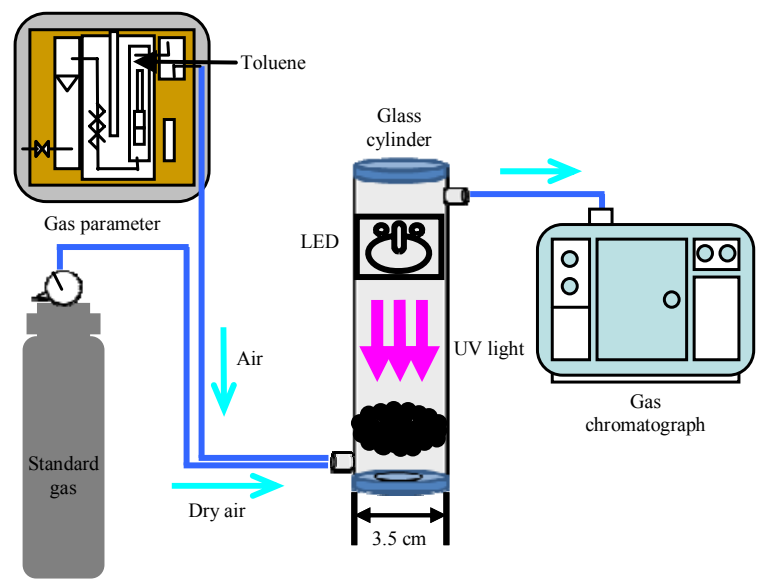

Fig. 1. Experimental setup. 


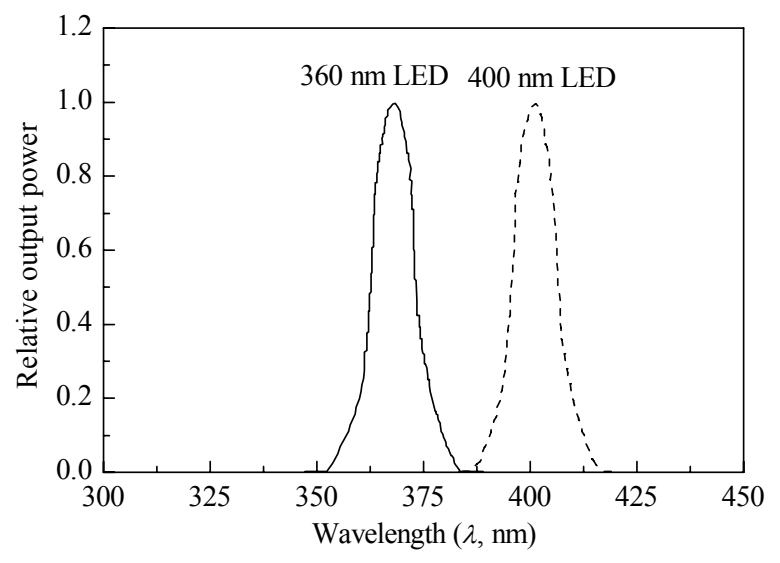

Fig. 2. Relative intensities of the UV LEDs. DC current $20 \mathrm{~mA}$, temperature $25^{\circ} \mathrm{C}$.

distance from the GAC to the LED, which was suspended over the composite was $2.5 \mathrm{~cm}$. The irradiative intensities were $0.6 \mathrm{~mW} / \mathrm{cm}^{2}$ and $0.12 \mathrm{~mW} / \mathrm{cm}^{2}$ for the $365-\mathrm{nm}$ and 400-nm LEDs, respectively. Toluene (99.8\%, Aldrich, 120 ppm) or methyl mercaptan gas ( $844 \mathrm{ppm}, \mathrm{v} / \mathrm{v}$ in nitrogen, RIGAS) was supplied to the glass cylinder at a constant flow rate $(220 \mathrm{ml} / \mathrm{min})$. Toluene concentrations in the inlet and outlet air of the glass cylinder were measured using a gas chromatograph (GC)/flame ionization detector (Perkin Elmer Photovac). An aliquot of the air stream at the cylinder outlet was also taken periodically in a 1-ml gas-tight syringe for the analysis of byproducts, which were determined using a GC/mass selective detector (Varian 450GC/220MS). The concentration of methyl mercaptan in the inlet or outlet air was determined by sampling with a 1-ml gas-tight syringe and analysis by a GC/flame photoionization detector.

\section{Results and discussion}

\subsection{Characterization of $\mathrm{TiO}_{2} / \mathrm{GAC}$ and metal-enhanced $\mathrm{TiO}_{2} / \mathrm{GAC}$}

The BET surface area, micropore (i.e. pore diameters $<2$ $\mathrm{nm})$ volume, and pore size of the $\mathrm{TiO}_{2} / \mathrm{GAC}$ and metalenhanced $\mathrm{TiO}_{2} /$ GAC composites are summarized in Table 1 . The uncoated GAC was found to have a surface area of $1187 \mathrm{~m}^{2} / \mathrm{g}$. The GAC composites that were obtained by spray-coating with the emulsion solution containing the catalysts and the silicone binder had slightly decreased surface areas between 1048 and $1168 \mathrm{~m}^{2} / \mathrm{g}$, depending upon the composite type. Similarly, Tao et al. [15] reported that the surface area of a $\mathrm{TiO}_{2} /$ enhanced GAC $\left(1380 \mathrm{~m}^{2} / \mathrm{g}\right)$ was less than that of pure GAC $\left(1472 \mathrm{~m}^{2} / \mathrm{g}\right)$. However, they did not find that the coating process deteriorated the sorption abilities of GAC for the VOCs. The difference in surface area for the various composites can be attributed to that of the
Table 1 Physical properties of $\mathrm{TiO}_{2}(\mathrm{I}) / \mathrm{GAC}, \mathrm{TiO}_{2}(\mathrm{II}) / \mathrm{GAC}$, and the four metal-enhanced $\mathrm{TiO}_{2} / \mathrm{GAC}$ composites

\begin{tabular}{lccc}
\hline Sample & $\begin{array}{c}\text { BET surface } \\
\text { area }\left(\mathrm{m}^{2} / \mathrm{g}\right)\end{array}$ & $\begin{array}{c}\text { Pore volume } \\
\left(\mathrm{cm}^{3} / \mathrm{g}\right)\end{array}$ & $\begin{array}{c}\text { Pore size } \\
(\mathrm{nm})\end{array}$ \\
\hline $\mathrm{GAC}$ & 1187 & 0.58 & 1.97 \\
$\mathrm{TiO}_{2}(\mathrm{I}) / \mathrm{GAC}$ & 1168 & 0.53 & 1.97 \\
$\mathrm{TiO}_{2}(\mathrm{II}) / \mathrm{GAC}$ & 1048 & 0.50 & 1.90 \\
$\mathrm{Ag}-\mathrm{TiO}_{2} / \mathrm{GAC}$ & 1059 & 0.51 & 1.92 \\
$\mathrm{Cu}_{-} \mathrm{TiO}_{2} / \mathrm{GAC}$ & 1063 & 0.52 & 1.87 \\
$\mathrm{Fe}-\mathrm{TiO}_{2} / \mathrm{GAC}$ & 1112 & 0.52 & 1.87 \\
$\mathrm{Zn}_{-} \mathrm{TiO}_{2} / \mathrm{GAC}$ & 1077 & 0.44 & 1.80 \\
\hline
\end{tabular}

raw GAC. The pore size and volume of each composite remained almost unchanged over the course of spraying and they showed tendencies similar to those of the above-mentioned surface areas. Therefore, considering all the data, the spray-coating solution did not influence the GAC surface area and thus the adsorption ability of $\mathrm{TiO}_{2} / \mathrm{GAC}$ or metal/TiO $/$ GAC and this ability did not decrease by spraying the sol solution onto the GAC. Similarly, Tao et al. [15] reported that the adsorption capacity of a $\mathrm{GAC}$ unit was almost identical to that of a $\mathrm{TiO}_{2} / \mathrm{GAC}$ unit, which they prepared for the removal of BTEX and methanol.

The FE-SEM images suggest that the GACs that were enhanced with $\mathrm{TiO}_{2}(\mathrm{I}), \mathrm{TiO}_{2}(\mathrm{II})$, and metal-enhanced $\mathrm{TiO}_{2}$ have similar porous structures (Fig. 3). The similar morphological structures of the composites are consistent with the SEM results of previous studies [15,25]. In these studies the surface characteristics of $\mathrm{TiO}_{2}$ and $\mathrm{TiO}_{2} / \mathrm{GAC}$ composites were investigated. Table 2 lists the weight percentages of each element in various composites as calculated from the EDS diagrams. The pure GAC mostly consisted of carbon and the detected $\mathrm{Mg}, \mathrm{Al}, \mathrm{Si}, \mathrm{Ca}$, and $\mathrm{Fe}$ come from impurities in GAC. However, for the other modified GACs the carbon percentages were lower than that found for the pure GAC. $\mathrm{TiO}_{2}(\mathrm{I}) / \mathrm{GAC}$ included up to $20 \% \mathrm{Ti}$ and the other composites were composed of $1.7 \%$ to $2.8 \%$ Ti. This result suggests that $\mathrm{TiO}_{2}$ particle aggregation increases on the GAC surface. For the $\mathrm{TiO}_{2}$ (II) composite, the reduced pore-size of methyl siloxane leads to a decrease in the particle size of $\mathrm{TiO}_{2}$ (II) compared to that of $\mathrm{TiO}_{2}(\mathrm{I})$, which results in a lower weight percentage of $\mathrm{Ti}$. The Ag-enhanced $\mathrm{TiO}_{2} / \mathrm{GAC}$ had the highest Ag weight percentage among the studied composites. Similarly, the $\mathrm{Cu}$-enhanced $\mathrm{TiO}_{2} / \mathrm{GAC}$, the Fe-enhanced $\mathrm{TiO}_{2} / \mathrm{GAC}$, and the Zn-enhanced $\mathrm{TiO}_{2} / \mathrm{GAC}$ had the highest $\mathrm{Cu}, \mathrm{Fe}$, and $\mathrm{Zn}$ weight percentages, respectively. This result is supported by the results of previous studies where the characteristics of metal-enhanced $\mathrm{TiO}_{2}$ were determined [21-24]. 

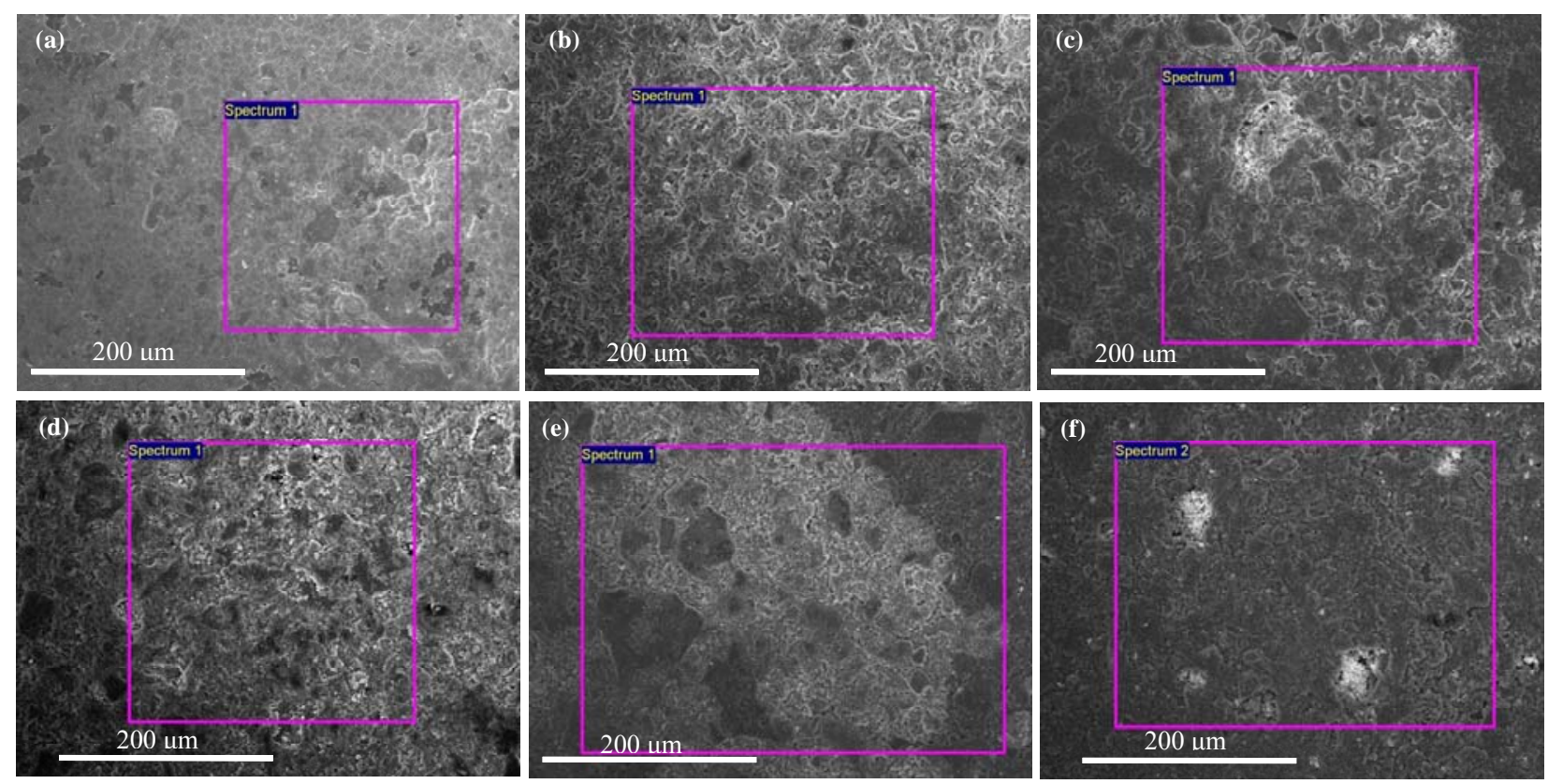

Fig. 3. FE-SEM photographs of different samples. (a) $\mathrm{TiO}_{2}(\mathrm{I}) / \mathrm{GAC}$; (b) $\mathrm{TiO}_{2}\left(\mathrm{I} / \mathrm{GAC}\right.$; (c) $\mathrm{Ag}-\mathrm{TiO}_{2} / \mathrm{GAC}$; (d) $\mathrm{Cu}-\mathrm{TiO}_{2} / \mathrm{GAC}$; (e) $\mathrm{Fe}-\mathrm{TiO} / 2 / \mathrm{GAC}$; (f) $\mathrm{Zn}-\mathrm{TiO}_{2} / \mathrm{GAC}$.

Table 2 Elemental composition of the GAC and the composites as measured by EDS

\begin{tabular}{|c|c|c|c|c|c|c|c|c|c|c|c|}
\hline \multirow{2}{*}{ Sample } & \multicolumn{11}{|c|}{ Elemental composition $(\%)$} \\
\hline & $\mathrm{C}$ & $\mathrm{O}$ & $\mathrm{Mg}$ & $\mathrm{Al}$ & $\mathrm{Si}$ & $\mathrm{Ti}$ & $\mathrm{Ca}$ & $\mathrm{Fe}$ & $\mathrm{Ag}$ & $\mathrm{Cu}$ & $\mathrm{Zn}$ \\
\hline GAC & 93 & 4.4 & 0.3 & 0.3 & 0.6 & 0 & 0.7 & 0.7 & 0 & 0 & 0 \\
\hline $\mathrm{TiO}_{2}(\mathrm{I}) / \mathrm{GAC}$ & 51 & 28 & 0.3 & 0.3 & 0.2 & 20 & 0 & 0.2 & 0 & 0 & 0 \\
\hline $\mathrm{TiO}_{2}(\mathrm{II}) / \mathrm{GAC}$ & 72 & 21 & 0.2 & 0.3 & 3.7 & 2.8 & 0 & 0 & 0 & 0 & 0 \\
\hline $\mathrm{Ag}-\mathrm{TiO}_{2} / \mathrm{GAC}$ & 86 & 10 & 0.3 & 0.2 & 0.4 & 2.7 & 0 & 0 & 0.4 & 0 & 0 \\
\hline $\mathrm{Cu}-\mathrm{TiO}_{2} / \mathrm{GAC}$ & 81 & 12 & 0.5 & 0.4 & 0.8 & 2.5 & 0.9 & 0.5 & 0 & 1.4 & 0 \\
\hline $\mathrm{Fe}-\mathrm{TiO}_{2} / \mathrm{GAC}$ & 91 & 5.7 & 0.2 & 0.3 & 0.5 & 1.7 & 0 & 0.6 & 0 & 0 & 0 \\
\hline $\mathrm{Zn}-\mathrm{TiO}_{2} / \mathrm{GAC}$ & 77 & 17 & 0.5 & 0.5 & 0.7 & 2.4 & 0.8 & 0.5 & 0 & 0 & 0.6 \\
\hline
\end{tabular}

\subsection{Removal efficiencies}

To examine the photocatalytic activities of the $\mathrm{TiO}_{2} / \mathrm{GAC}$, the efficiency of toluene removal using the pure GAC and the $\mathrm{TiO}_{2} / \mathrm{GAC}$ were determined (Fig. 4). At $t=0$, the outlet toluene concentrations indicate a range of $38 \%$ to $50 \%$ of the inlet concentration (120 ppm), which means that about half the toluene passed through the cylinder without contacting the adsorbent. One reason that $\mathrm{C}$ at $t=0$ was not equal to zero is that the adsorbent was spread loosely over the glass plate. Because photocatalytic oxidation occurs on the surface irradiated by UV-rays and to increase the adsorption capacity of each unit amount of the composite, the quantity of the composite used was minimized to just cover the surface of the glass plate; i.e., the GAC was not allowed to pile up. This procedure is supported by previous studies $[15,25]$ wherein UV irradiated $\mathrm{TiO}_{2}$ effectively regenerated the adsorption sites on the activated carbon.

Without illumination, both the $\mathrm{GAC}$ and $\mathrm{TiO}_{2} / \mathrm{GAC}$ composites gave immediate breakthroughs and about $1 \mathrm{~h}$ later these adsorbents were depleted. Upon $400 \mathrm{~nm}$ radiation with one LED lamp on the $\mathrm{TiO}_{2}$ (I) composite, the adsorption capacity increased and the breakthrough as well as depletion times of the absorption curve were extended to about 0.5 and $2.5 \mathrm{~h}$, respectively. This confirmed that the $\mathrm{TiO}_{2}$ catalyst on the surface of the GAC was activated by near $\mathrm{UV}(400 \mathrm{~nm})$ radiation. By increasing the number of 400 $\mathrm{nm}$ LEDs from one to four, an increase in the depletion time was found for the composite and upon replacing binder I with binder II led to an increase in the lifetime of the composite. Smaller particle size $\mathrm{TiO}_{2}$ has been postulated be more photoactive than larger particle size $\mathrm{TiO}_{2}$ because of a larger surface area [25].

Upon irradiation with a 360-nm LED lamp, the $\mathrm{TiO}_{2}(\mathrm{I}) / \mathrm{GAC}$ composite increased its adsorption capacity dramatically. The $\mathrm{TiO}_{2}$ (II) composite showed an adsorption curve similar to that of $\mathrm{TiO}_{2}(\mathrm{I})$. The price of LED lamps that emit wavelengths around $360 \mathrm{~nm}$ are about 10 times higher 


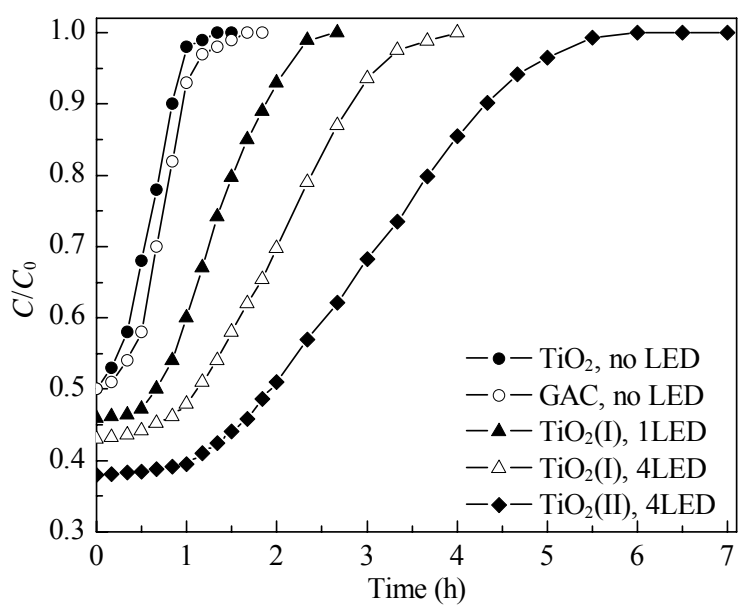

Fig. 4. Comparison of toluene removal by $\mathrm{GAC}$ and $\mathrm{TiO}_{2} / \mathrm{GAC}$ under the $400 \mathrm{~nm}$ irradiation. $C_{0}$ and $C$ represent inlet (120 ppm, ca. $220 \mathrm{ml} / \mathrm{min}$ ) and outlet concentrations of toluene, respectively.

than those that emit around $400 \mathrm{~nm}$. Although LED lamps are very useful for the fabrication of small abatement equipment and for maximizing the efficiency of VOC photooxidation, the high cost of shortwave LEDs prohibits their application in industry [26,27]. Therefore, in this study we investigated the maximum reactivity of $\mathrm{TiO}_{2}$ at $400 \mathrm{~nm}$ instead of at $<380 \mathrm{~nm}$ upon the addition of transition metal ions to $\mathrm{TiO}_{2}$. This wavelength shift is supported by previous studies wherein the UV-Vis diffuse reflectance spectra of metal-doped photocatalysts were obtained [21-24,28].

Figure 5 shows the toluene concentrations in the outlet stream from the cylinder filled with the different element-enhanced $\mathrm{TiO}_{2} / \mathrm{GAC}$ under $400 \mathrm{~nm}$ LED irradiation. The addition of $\mathrm{Fe}^{3+}, \mathrm{Cu}^{2+}$, and $\mathrm{Ag}^{+}$to $\mathrm{TiO}_{2}$ had a negative effect on the adsorption capacities of the composite and for $\mathrm{Zn}^{2+}$, the $\mathrm{Zn}$-enhanced $\mathrm{TiO}_{2} / \mathrm{GAC}$ composite had almost the

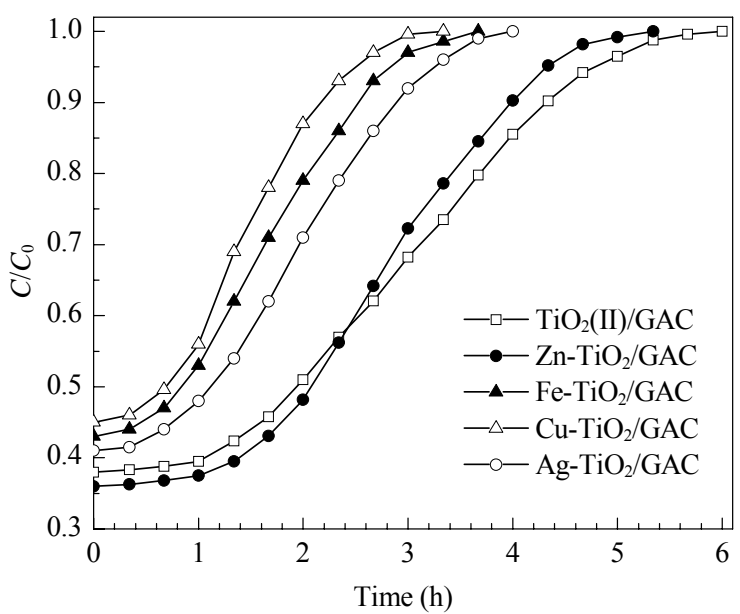

Fig. 5. Toluene concentration ratios of the inlet streams to the outlet streams upon passing though the metal-assisted composites upon 400 nm irradiation. same adsorption curve as that of $\mathrm{TiO}_{2}(\mathrm{II}) / \mathrm{GAC} \cdot \mathrm{Fe}^{3+}$ and $\mathrm{Cu}^{2+}$ resulted in a red shift [29] and did not show such an effect. A few studies claim that the transition metals added to $\mathrm{TiO}_{2}$ move the absorption edge to a longer wavelength [30-32]. The negative effects of transition metal addition on the adsorption capacities of the composites suggest that our metal doping procedure is different to that found in the literature [22]. Only zinc was found to improve the removal efficiency of the $\mathrm{TiO}_{2} / \mathrm{GAC}$ composite. Although the reason is unclear, this pattern is likely due to the combined effects of the physical properties of the four types of metal-enhanced $\mathrm{TiO}_{2} / \mathrm{GAC}$ (Table 1) and the elemental weights in the composites (Table 2). Previous studies $[33,34]$ have reported an effective photocatalytic degradation of airborne toluene under conventional UV-lamp irradiation.

To evaluate the removal efficiencies of the prepared composites toward an odorous gas, methyl mercaptan was used as a model compound for the photoreaction. This compound is known to cause malodor in food waste and industrial wastewater $[19,20]$. Figure 6 shows that a certain ratio of outlet per inlet concentration of methyl mercaptan passed through the glass cylinder. The silver-enhanced $\mathrm{TiO}_{2} / \mathrm{GAC}$ composite had the lowest adsorption capacity among the photocatalyst composites that were irradiated at $400 \mathrm{~nm}$. Upon the addition of $\mathrm{Fe}$ or $\mathrm{Cu}$, the depletion time of the corresponding composite was shortened slightly and we suggest that zinc increases the breakthrough time of the zinc-enhanced $\mathrm{TiO}_{2} / \mathrm{GAC}$ composite. These results are likely due to the different characteristics of the surveyed transition metals ( $\mathrm{Ag}, \mathrm{Fe}, \mathrm{Cu}$, and $\mathrm{Zn}$ ) as reported in previous studies [21-25]. Another possible cause is a photoadsorption effect of the composites. Nevertheless, further study is required to verify this assertion because various

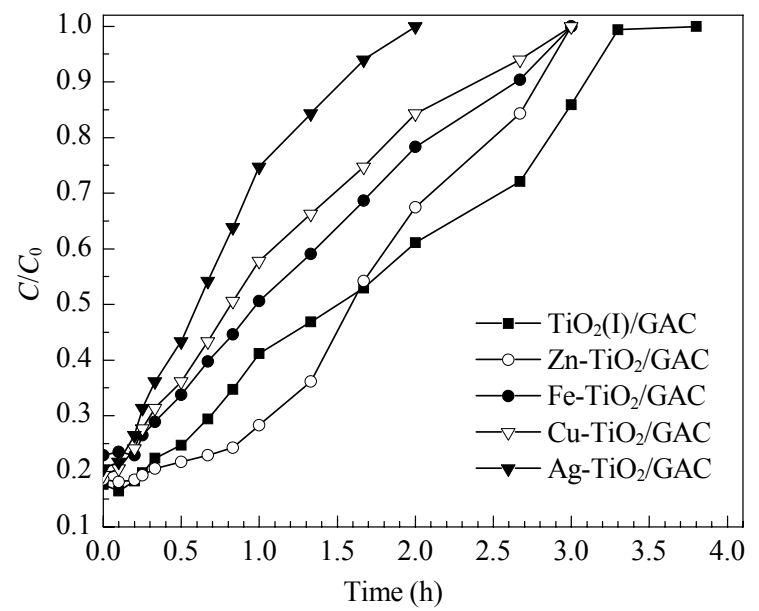

Fig. 6. Methyl mercaptan concentration ratios of the inlet streams to the outlet streams upon passing through the metal-assisted composites under $400 \mathrm{~nm}$ irradiation. 
factors can influence their adsorption and photochemical activities.

\section{Conclusions}

LED lamps that emit UV wavelengths can increase the adsorption capacity of GAC upon impregnation with a $\mathrm{TiO}_{2}$ photocatalyst or a $\mathrm{TiO}_{2} /$ co-catalyst. $400 \mathrm{~nm}$ irradiation is capable of activating ordinary $\mathrm{TiO}_{2}$ photocatalysts and this dramatically increases the adsorption capacity of the adsorbent. The radiation from a $400 \mathrm{~nm}$ LED lamp revealed a large difference in $\mathrm{TiO}_{2}$ photocatalytic activity depending on the crosslink agent. The particle size of the $\mathrm{TiO}_{2}$ that was coated on the adsorbent was found to be an important parameter for the photodegradation activity of the composite. Transition metal ions added to $\mathrm{TiO}_{2}$ could be activated with near UV radiation emitted by a low-cost $400 \mathrm{~nm}$ LED. However, the addition of metal ions did not have a positive effect but decreased the adsorption capacities compared with that of a simple $\mathrm{TiO}_{2} / \mathrm{GAC}$ composite, except for zinc ion as a slight increase in the adsorption of both toluene and methyl mercaptan was found. Although impregnating the $\mathrm{TiO}_{2}$ catalyst with transition metals did not increase the photodestruction efficiency toward VOCs with $400 \mathrm{~nm}$ LED radiation as much as with $360 \mathrm{~nm}$ irradiation, the $\mathrm{TiO}_{2}$ impregnation of GAC increased the VOC adsorption capacity and prolonged the threshold and depletion time of the adsorbent. Further investigations into a safe, energy efficient, compact VOC abatement system are recommended to extend the renewal time to be substantially higher than that of the bare GAC using photocatalyst composites and tiny inexpensive LEDs.

\section{Acknowledgements}

The authors would like to thank the Korea Institute of Environmental Science and Technology for financially supporting this research.

\section{References}

1 Cetin E, Odabasi M, Seyfioglu R. Sci Total Environ, 2003, 312: 103

2 Liu Y, Shao M, Fu L, Lu S, Zheng L, Tang D. Atmos Environ, 2008, 42: 6247

3 Roukos J, Riffault V, Locoge N, Plaisance H. Environ Poll, 2009, 157: 3001

4 OEHHA (Office of Environmental Health Hazard Assessment) Proposition 65 Status Report Safe Harbor Levels: No Significant Risk Levels for Carcinogens and Maximum Allowable Dose Levels for Chemicals Causing Reproductive Toxicity.
California Environmental Protection Agency, OEHHA, Sacramento, CA, 2003

5 Atkinson R, Arey J. Atmos Environ, 2003, 37(suppl. 2): 197

6 Destallats H, Lunden M M, Singer B C, Coleman B K, Dodgson A T, Weschler C J, Nazaroff W W. Environ Sci Technol, 2006, 40: 4421

7 Liu J, Huang Z H, Wang Z S, Kang F Y. J Environ Sci-China, 2004, 16: 53

8 Giraudet S, Pre P, Tezel H, Le Cloirec P. Carbon, 2006, 44: 2413

9 Sasaki T, Matsumoto A, Yamashita Y. Colloid Surf A, 2008, 325: 166

10 Yu F D, Luo L G, Grevillot G. Chem Eng Proc, 2007, 46: 70

11 Deveau P A, Arsac F, Thivel P X, Ferronato C, Delpech F, Chovelon J M, Kaluzny P, Monnet C. J Hazard Mater, 2007, 144: 692

12 Qi H, Sun D Zh, Chi G Q. J Environ Sci-China, 2007, 19: 1136

13 Li D P, Qu J H. J Environ Sci-China, 2009, 21: 713

14 Shiraishi F, Yamaguchi S, Ohbuchi Y. Chem Eng Sci, 2003, 58: 929

15 Tao Y, Wu C-Y, Mazyck D W. Chemosphere, 2006, 65: 35

$16 \mathrm{http}: / /$ en.wikipedia.org/wiki/Light-emitting_diode, 2010

17 Ghosh J P, Langford C H, Achari G. J Phys Chem A, 2008, 112: 10310

18 Ghosh J P, Sui R, Langford C H, Achari G, Berlinguette C P. Water Res, 2009, 43: 4499

19 Tamai H, Nagoya H, Shiono T. J Colloid Interf Sci, 2006, 300: 814

20 Corrêa S M, Arbilla G. Atmos Environ, 2008, 42: 6721

21 Zhang X W, Zhou M H, Lei L C. Mater Chem Phys, 2005, 91: 73

22 Kim Y, Lee J, Jeong H, Lee Y, Umb M H, Jeong K M, Yeo M K, Kang M. J Ind Eng Chem, 2008, 14: 396

23 Araña J, Peña Alonso A, Doña Rodríguez J M, Herrera Melián J A, González Díaz O, Pérez Peña J. Appl Catal B, 2008, 78: 355

24 Melghit K, Bouziane K. J Alloy Comp, 2008, 453: 102

25 Ao Y H, Xu J J, Fu D G, Shen X W, Yuan C W. Colloid Surf A, 2008, 312: 125

26 Chen H W, Ku Y, Irawan A. Chemosphere, 2007, 69: 184

27 Matsumoto T, Iyi N, Kaneko Y, Kitamura K, Ishihara S, Takasu Y, Murakami Y. Catal Today, 2007, 120: 226

28 Yu J G, Xiang Q J, Zhou M H. Appl Catal B, 2009, 90: 595

29 Rehman S, Ullah R, Butt A M, Goher N D. J Hazard Mater, 2009, 170: 560

30 Yamashita H, Harada M, Misaka J, Takeuchi M, Ikeue K, Anpo M. J Photochem Photobiol A, 2002, 148: 257

31 Chen S F, Zhao W, Wei L, Zhang S J. Appl Surf Sci, 2008, 255: 2478

32 Zang X W, Lei L C. Mater Lett, 2008, 62: 895

33 Zhou M H, Yu J G, Liu S W, Zhai P C, Huang B B. Appl Catal B, 2009, 89: 160

34 Liu S W, Yu J G, Mann S. J Phys Chem C, 2009, 113: 10712 